\title{
Viscoelastic Properties of Branched Polymers. I. At the Undiluted State
}

\author{
Yoshinobu Isono, Teruo FuJImoto, * Hisao InAGAKI, \\ Masato SHISHIDO, and Mitsuru NAGASAWA \\ Department of Synthetic Chemistry, Nagoya University, \\ Chikusa-ku, Nagoya 464, Japan.
}

(Received October 5, 1979)

\begin{abstract}
The viscoelastic properties of four-armed, star-shaped polystyrenes having narrow molecular weight distributions were studied in a undiluted state by the tensile stress relaxation method. The steady-flow viscosity, the steady-state compliance and other rheological parameters were determined from the relaxation modulus master curves. The molecular weight dependences of these parameters were compared with those of linear and comb-shaped polymers.

KEY WORDS Star-Shaped Polymer / Branched Polymer / Stress

Relaxation / Steady-Flow Viscosity / Steady-State Compliance /

Entanglement /
\end{abstract}

The viscoeleastic properties of linear polymers, at least in the linear region of deformation, have extensively been studied both experimentally and theoretically. ${ }^{1,2}$ In the case of branched polymers, too, a considerable number of papers, ${ }^{3-5}$ including a paper of Masuda et al..$^{6}$ and that of Utracki et al. ${ }^{7}$ on a sample similar to ours have been published. However, our knowledge on the viscoelastic properties of branched polymers does not yet seem sufficient. For example, although the steady-state compliance $J_{\mathrm{e}}$ of star-shaped polymers are lower than those of the corresponding linear polymers in dilute and moderately concentrated solutions, ${ }^{8,11,12}$ as predicted theoretically, ${ }^{13-15}$ it was found that the $J_{\mathrm{e}}$ of certain branched polymers was much higher than that of the corresponding linear polymers at the undiluted state. ${ }^{6,9,10}$ Moreover, enhancements in zero-shear viscosity $\eta^{\circ}$ due to branching, relative to $\eta^{\circ}$ of the corresponding linear polymers, were reported for polyethylene, ${ }^{16,17}$ polyisoprene ${ }^{18}$ and polybutadiene, ${ }^{19,20}$ whereas such enhancements were not found for poly $(\alpha \text {-methylstyrene })^{8}$ and polystyrene..$^{6,7,9-11}$ An interesting theory ${ }^{4,18}$ has been given to this phenomenon, but it seems worth

* Present Address: Department of Material Science and Technology, Technological University of Nagaoka, Nagaoka, Niigata 949-54, Japan. while to accumulate more experimental works.

The visoelastic parameters, especially the steadystate compliance, of branched polymers are greatly influenced by polydispersities with respect to molecular weight and/or the degree of branching. Combshaped polystyrenes used in previous works ${ }^{9,10}$ have distributions with respect to the degree of branching. One purpose of this work is to eliminate the effect of the polydispersity, using star-shaped polymers of high purity. The molecular weight dependences of $\eta^{\circ}, J_{\mathrm{e}}$ and other viscoelastic parameters of star-shaped polystyrenes with four branches are determined by stress relaxation experiments and compared with the conclusions obtained with highly branched, comb-shaped polystyrenes $^{9,10}$ as well as with the data of linear polystyrenes. ${ }^{10}$

\section{EXPERIMENTAL}

\section{Samples}

The four-armed, star-shaped polystyrenes having narrow molecular weight distributions were prepared by the method of Bywater et al., ${ }^{21}$ i.e., by a coupling reaction of polystyryllithium with 1,2bis(methyldichlorosilyl)ethane. The active chain end of polystyryllithium was converted to isoprenyllithium in order to make the coupling reaction easier. 
The ratio of polystryllithium to the silicone-chlorine bond was between 2 and 4 so as to ensure the complete coupling.

Fractionation of the polymers obtained was carefully carried out by two different precipitation fractionation methods, i.e., by precipitating the samples from benzene solution with methanol and also by changing the temperature of cyclohexane solution. The content of four-armed, star-shaped polymers was increased up to about $95 \%$ by these methods.

The sample rich in the four-armed polymers was further fractionated by elution chromatography using cyclohexane. The details about the apparatus

a

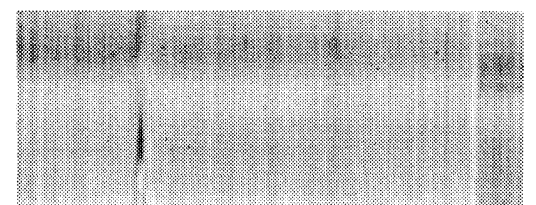

b

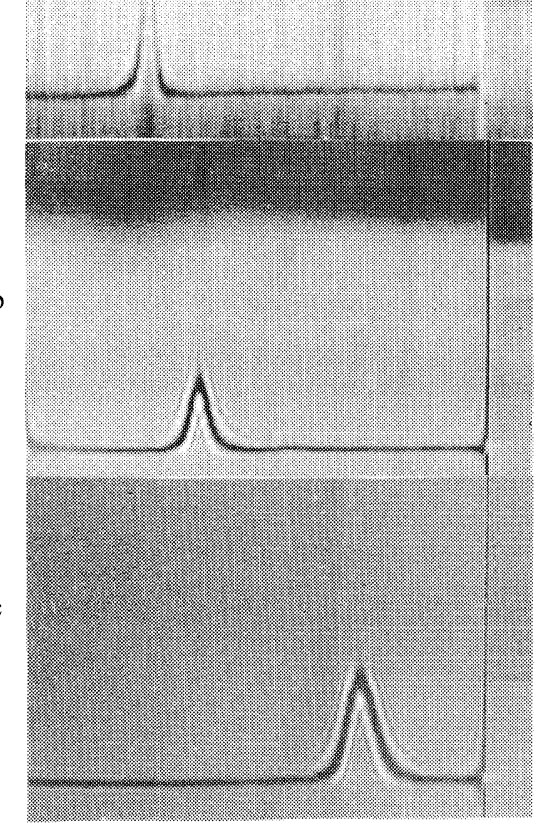

Figure 1. Examples of the sedimentation patterns of the 4-armed, star-shaped polystyrenes. (a) CS-81; solvent, cyclohexane; $35^{\circ} \mathrm{C}$; concentration, $0.19 \mathrm{~g} \mathrm{dl}^{-1}$; speed of rotation, $59780 \mathrm{rpm}$; angle $70^{\circ}$; time, $34 \mathrm{~min}$. (b) CS-60; solvent, cyclohexane; $35^{\circ} \mathrm{C}$; concentration, $0.16 \mathrm{~g} \mathrm{dl}^{-1}$; speed of rotation, $59780 \mathrm{rpm}$; angle, $70^{\circ}$; time, $43 \mathrm{~min}$. (c) CS-25; solvent, cyclohexane; $35^{\circ} \mathrm{C}$; concentration, $0.26 \mathrm{~g} \mathrm{dl}^{-1}$; speed of rotation, $59780 \mathrm{rpm}$; angle, $70^{\circ}$; time $27 \mathrm{~min}$.
Table I. Molecular characteristics of the four-armed, star-shaped polystyrenes

\begin{tabular}{cccc}
\hline \multirow{2}{*}{ Sample code } & \multicolumn{2}{c}{ Molecular weight } & Branch \\
\cline { 2 - 3 } & $M_{n} \times 10^{-5}$ & $M_{w} \times 10^{-5}$ & $M_{n} \times 10^{-5}$ \\
\hline CS-81 & $7.5_{0}$ & $7.6_{0}$ & $1.8_{5}$ \\
CS-60 & $4.8_{8}$ & - & $1.2_{2}$ \\
CS-25 & $2.8_{0}$ & - & $0.71_{5}$ \\
\hline
\end{tabular}

for the elution chromatography and operations have already been reported. ${ }^{22}$ Sedimentation patterns of the samples used, taken with an analytical ultracentrifuge Beckman Spinco model-E, are shown in Figure 1, to show the purity of the samples.

The number and weight-average molecular weights of the samples were determined by osmometry and light-scattering, using a Hewlett-Packard highspeed membrane osmometer 502 and automatic light-scattering photometer Fica-50, respectively. The osmometry was carried out in toluene at $25^{\circ} \mathrm{C}$, while the light-scattering was measured in cyclohexane at $35^{\circ} \mathrm{C}$. The molecular characteristics of the samples thus determined are listed in Table I. A sample having a higher molecular weight (about $1.4 \times 10^{6}$ ) was also prepared but was degradated during the fractionation process.

\section{Measurements}

Measurements of the relaxation modulus were carried out by the tensile-stress relaxation method with the apparatus reported previously. ${ }^{23}$ Films were made by evaporating the solvent from $5-10 \%$ dichloromethane solutions of the samples on a glass floating on mercury in a dry box. The films of about $0.2 \mathrm{~mm}$ thickness thus prepared were fully dried in a vacuum oven under $10^{-2} \mathrm{mmHg}$. The oven temperature was raised gradually from room temperature to about $110^{\circ} \mathrm{C}$, kept at the temperature for at least $12 \mathrm{~h}$ and then gradually lowered to room temperature.

\section{RESULTS AND DISCUSSION}

Examples of the change in relaxation modulus $E$ with time are shown in Figure 2. All data at various temperatures are shifted on the curve at a reference temperature, $140^{\circ} \mathrm{C}$, assuming the time-temperature superposition principle. The shift factor $a_{\mathrm{T}}$ was determined by the method of Plazek. ${ }^{24}$ The details of 
Viscoelastic Properties of Branched Polymers. I.

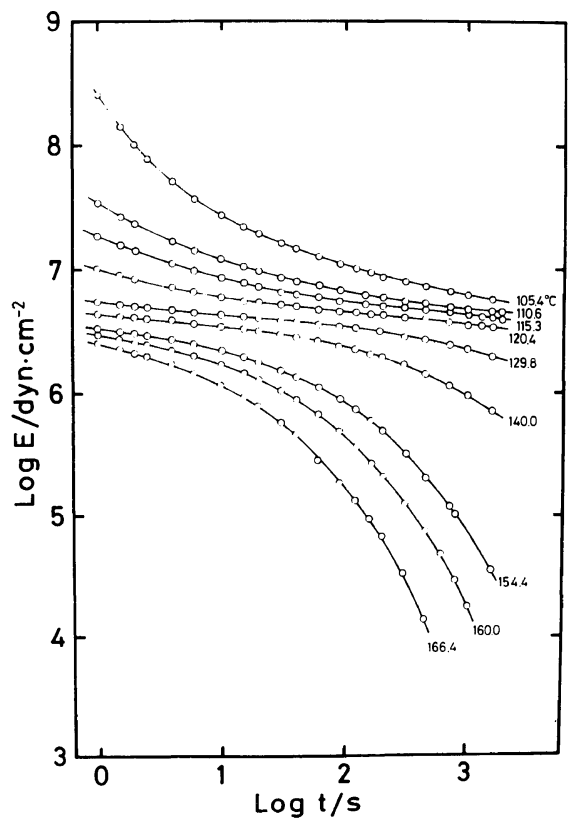

Figure 2. Typical examples of experimental relaxation moduli double-logarithmically plotted against time at various temperatures. The sample is four-armed, starshaped polystyrene CS- 81 in the undiluted state. this procedure were reported previously. ${ }^{25}$ The shift factor for four-armed polystyrenes is in good agreement with those for linear ${ }^{10}$ and comb-shaped polystyrenes, ${ }^{9,10}$ as shown in Figure 3.

The relaxation modulus $(E)$ master curves for undiluted four-armed, star-shaped polystyrenes thus obtained are shown in Figure 4. For comparison, examples of the relaxation modulus master curves for the undiluted linear and comb-shaped polystyrenes, as reported previously, ${ }^{9,10}$ are shown by broken and solid lines, respectively, in Figure 4. It can be pointed out that the heights of the plateau

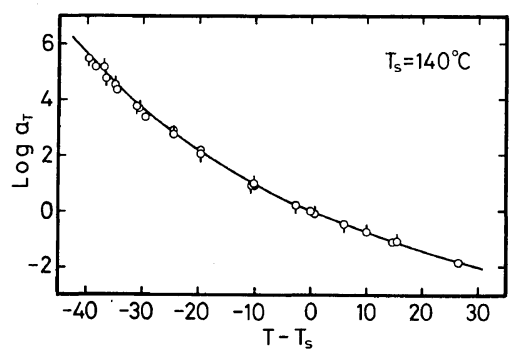

Figure 3. Shift factors $a_{\mathrm{T}}$ for four-armed, star-shaped polystyrenes. Symbols $\bigcirc, O$, and $\bigcirc$ show the data for CS- $81,-60$, and -25 , respectively. The solid line shows the data for linear and comb-shaped polystyrenes. ${ }^{9,10}$

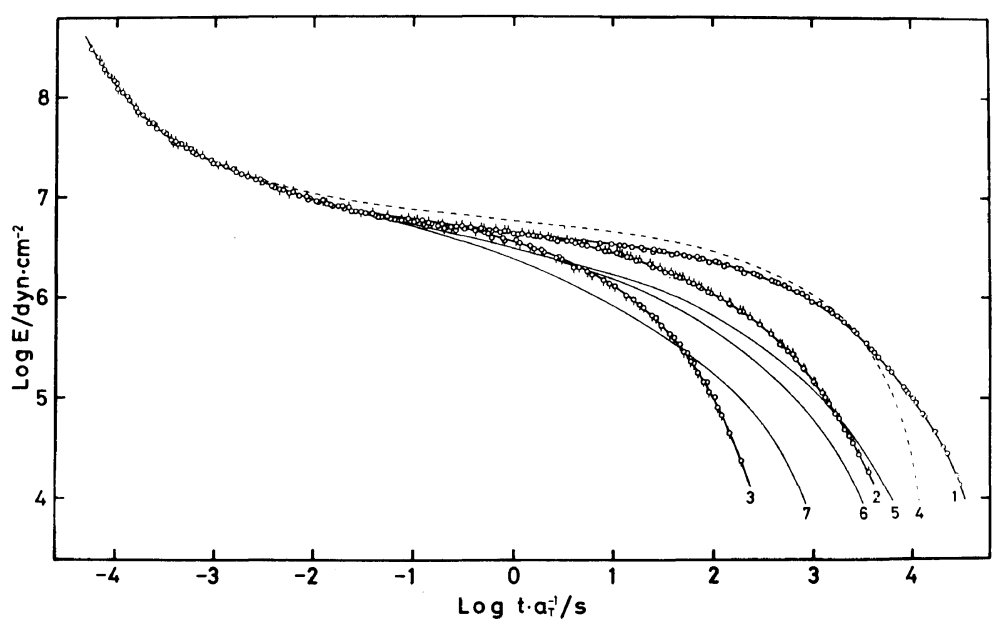

Figure 4. Relaxation modulus master curves for various types of polymers at the undiluted state. Temperature, $140^{\circ} \mathrm{C}$. Curves $1(\mathrm{O}), 2(\bigcirc)$, and $3(\bigcirc)$ show the data for star-shaped polystyrenes CS-81, -60 , and -25 , respectively. The broken line 4 show the data for linear polystyrene with $M_{w}=3.68 \times 10^{5}$, reported previously. ${ }^{10}$ Solid lines 5,6 ; and 7 show the data for comb-shaped polystyrenes $F-3,-6$, and -12 , respectively, reported previously. ${ }^{9}$ 
regions of the star-shaped polymers are lower than that of linear polymer, but higher than those of the comb-shaped polymers. Moreover, by comparing the curves 2, 4, and 7 in Fig. 4, it can be shown that the maximum relaxation times of the samples having the same molecular weight become shorter in the order of linear, star-shaped and comb-shaped polymers. There is no detectable difference among the relaxation moduli of star-shaped, comb-shaped and linear polymers in the transition region.

The relaxation spectra were calculated from the relaxation modulus master curves in Figure 4 by using the second approximation method of Schwarzl and Staverman ${ }^{26}$ and are shown in Figure 5. It was reported for the linear polymers ${ }^{25}$ that two peaks in $H(\tau)$ showing the intramolecular motion and molecular motion are clearly separated and that a minimum appears in $H(\tau)$ if the molecular weight distributions of samples are narrow enough and their molecular weights are high enough. In the curves of the four-armed, star-shaped polymers in Figure 5 (curves 1,2 , and 3 ), however, the minima in $H(\tau)$ disappear or much less clearly found. The disappearance of minima in $H(\tau)$ of the present four-armed samples may be caused by the insufficient quasinetwork formation of the present molecules, as will be discussed later.

The steady-flow viscosity $\eta^{\circ}$ is calculated from the relaxation modulus master curves using eq 1 .

$$
\eta^{\circ}=\frac{1}{3} \int_{-\infty}^{\infty} t E(t) \mathrm{d}(\ln t)
$$

The $\log \eta^{\circ} v s . \log M$ curves for undiluted star-shaped, comb-shaped ${ }^{9,10}$ and linear polystyrenes ${ }^{10,27,28}$ are shown in Figure 6. It is clear that $\eta^{\circ}$ of four-armed, star-shaped polystyrenes is lower than that of linear polystyrenes having the same molecular weights, but higher than that of the corresponding highly branched, comb-shaped polystyrenes. Moreover, $\eta^{\circ}$ of both the star-shaped and combshaped polystyrenes increases in a $4.3 \mathrm{rd}$ power proportion to molecular weight, if the degree of branching is kept constant. It was reported ${ }^{16-20}$ that the slopes in the double-logarithmic plot of zeroshear viscosity $\eta^{\circ} v s$. molecular weight $M$ for branched polyisoprenes, polybutadienes and polyethylenes are much steeper than those for the corresponding linear polymers and, consequently, that $\eta^{\circ}$ of branched polymers are higher than those for the corresponding linear polymers if the molecular weights are high enough. In our data with polystyrenes, the reversal $\eta^{\circ}$ could not be detected in the present molecular weight range, though the slope in $\log \eta^{\circ} v s . \log M$ plot of branched polystyrenes is higher than that of linear polystyrenes in accordance with the results of Masuda et al. ${ }^{6}$ and of Utracki et al. ${ }^{7}$

The steady-state compliance $J_{\mathrm{e}}$ is calculated from

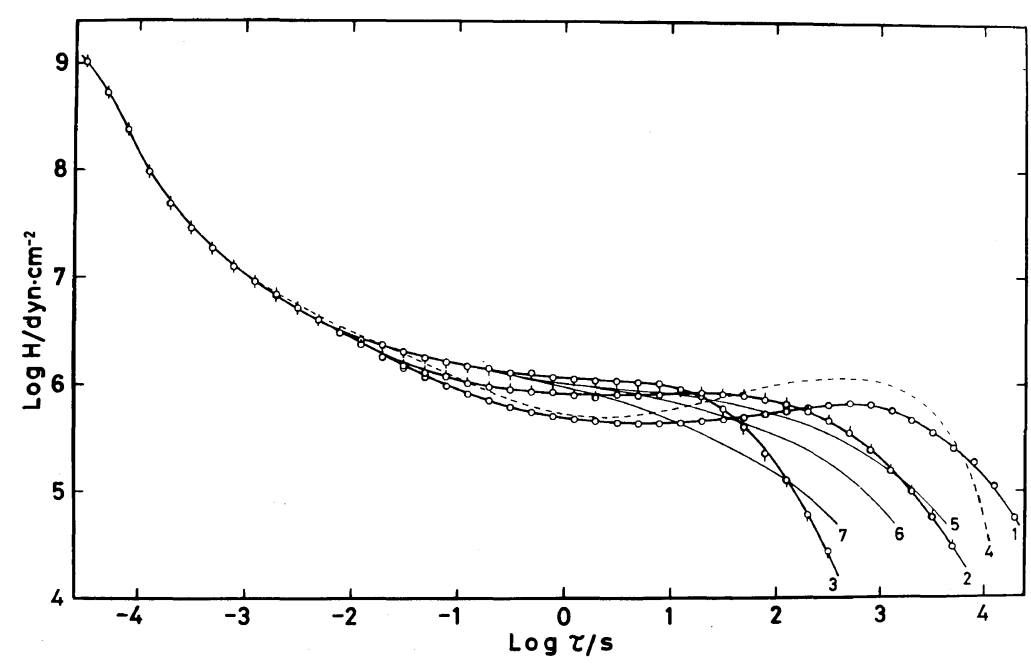

Figure 5. Relaxation spectra of star-shaped, comb-shaped and linear poly(styrene)s in the undiluted state. Temperature $140^{\circ} \mathrm{C}$. The indicated numbers have the same meaning as in Figure 4. 


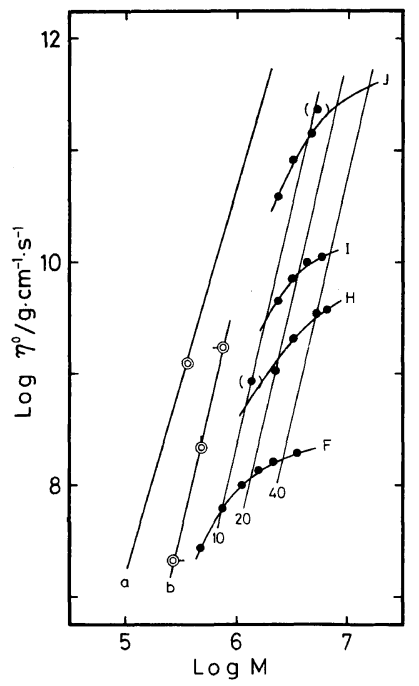

Figure 6. Molecular weight dependences of the steadyflow viscosity $\eta^{0}$ for various types of polymers at the undiluted state. Temperature $140^{\circ} \mathrm{C}$. Symbols (a) with pip-left, up and right show the data for four-armed, starshaped polystyrenes CS-81, -61 , and -25 , respectively. Symbol () without pip shows the data for linear polystyrene with $M_{w}=3.68 \times 10^{5}$, reported previously. ${ }^{10}$ Filled circles show the data for comb-shaped polystyrenes, reported previously. ${ }^{9}$ The letters J. I. H, and $F$ are the sample codes of various series of combshaped polymers. ${ }^{9}$ The solid line a shows the molecular weight dependences of $\eta^{0}$ of linear polystyrenes reported by Akovali et al..$^{27,28}$ and others. ${ }^{10}$ The solid line b shows the molecular weight dependence of $\eta^{0}$ of four-armed, star-shaped polystyrenes. The solid lines 10,20 , and 40 show the estimated molecular weight dependence of $\eta^{0}$ of comb-shaped polystyrenes having the number of branching of 10,20 , and 40 , respectively.

the relaxation modulus master curves using eq 2 .

$$
J_{\mathrm{e}}=\frac{1}{3 \eta^{2}} \int_{-\infty}^{\infty} t^{2} E(t) \mathrm{d}(\ln t)
$$

The plot of $\log J_{\mathrm{e}} v s . \log M$ for undiluted star-shaped polystyrenes are shown in Figure 7. For comparison, the data for linear ${ }^{10,29-31}$ and comb-shaped polystyrenes ${ }^{9,10}$ reported previously are also shown in Figure 7. It is clear from this figure that $J_{\mathrm{e}}$ of the present star-shaped polymers is higher than that of the linear polymers, if they are compared at the same molecular weight. Moreover, $J_{\mathrm{e}}$ of the star-shaped polymers is proportional to molecular weight in the present molecular weight range $\left(M=2.8 \times 10^{5}-\right.$

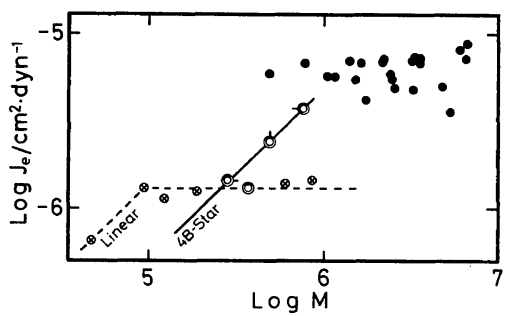

Figure 7. Molecular weight dependences of the steadystate compliance for various types of polymers at the undiluted state. The symbol $\otimes$ shows the data for linear polystyrenes reported by Plazek et al. ${ }^{29-31}$ Other symbols are the same as in Figure 6.

$\left.7.5 \times 10^{5}\right)$. In the case of linear polymer melts, it was pointed out ${ }^{1,2,4,32}$ that if the molecular weight $M$ is high enough to make that the polymer molecules form a quasi-network, $J_{\mathrm{e}}$ becomes independent of $M$; but if $M$ is below a critical value, $J_{\mathrm{e}}$ is proportional to $M$, as shown by the theories of Rouse, ${ }^{33}$ Bueche,${ }^{34}$ and Zimm. ${ }^{35}$ The critical molecular weight for quasi-network formation of linear polystyrene melts determined by $J_{\mathrm{e}}$ is about $1.0 \times 10^{5}$ $1.3 \times 10^{5} .^{2}$ If the molecular weight dependence of $J_{\mathrm{e}}$ of branched polymers is determined by a mechanism similar to that in linear polymers, then, these experimental facts show that in four-armed, star-shaped polystyrene melts, even a sample having a molecular weight of $1.85 \times 10^{5}$ of a branch is not sufficient to form the quasi-network structure. This problem will be discussed in more detail in a future paper. ${ }^{36}$ Nevertheless, it is certain that $J_{\mathrm{e}}$ is increased by branching in the undiluted state if $J_{\mathrm{e}}$ of linear and branched polymers are compared at the same molecular weight. In a previous paper, ${ }^{9}$ Fujimoto et al. went on the assumption that the enhancement in $J_{\mathrm{e}}$ of comb-shaped polymers relative to linear polymers was caused by the existence of branching rather than by the polydispersity of samples. The present data confirm this prediction.

The maximum relaxation time $\tau_{\mathrm{m}}$ and the modulus associated with the maximum relaxation time $E_{\mathrm{m}}$, showing the behavior of the polymer in the terminal region, are obtained from the linear plot of $\ln E(t)$ and $t .{ }^{37}$ The values obtained are shown in Table II and in Figures 8 and 9, respectively. The graph of $\tau_{\mathrm{m}}$ for linear and branched polymers is very similar to the graph of $\eta^{\circ}$.

From the above results, it may be concluded that 
Table II. Rheological parameters of the four-armed, star-shaped polystyrenes

\begin{tabular}{|c|c|c|c|c|}
\hline \multirow{2}{*}{ Sample code } & $\eta^{\circ}$ & $J_{\mathrm{e}}$ & $\tau_{\mathrm{m}}$ & $E_{\mathrm{m}}$ \\
\hline & poise & $\mathrm{cm}^{2} \mathrm{dyn}^{-1}$ & $\mathrm{~s}$ & dyn $\mathrm{cm}^{-2}$ \\
\hline CS-81 & $1.69 \times 10^{9}$ & $3.62 \times 10^{-6}$ & $1.26 \times 10^{4}$ & $1.1 \times 10^{5}$ \\
\hline CS-60 & $2.19 \times 10^{8}$ & $2.40 \times 10^{-6}$ & $1.78 \times 10^{3}$ & $1.4 \times 10^{5}$ \\
\hline CS-25 & $2.13 \times 10^{7}$ & $1.43 \times 10^{-6}$ & $1.26 \times 10^{2}$ & $2.5 \times 10^{5}$ \\
\hline
\end{tabular}

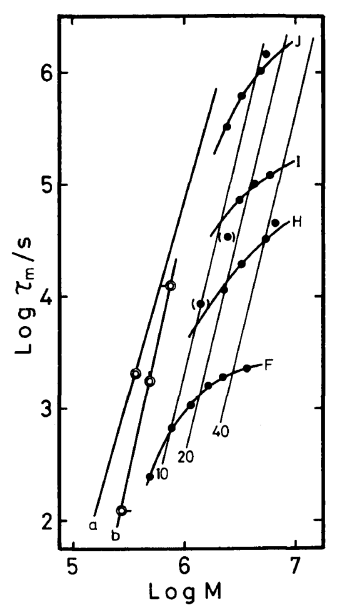

Figure 8. Molecular weight dependences of the maximum relaxation time. The saymbols and the indicated letters and numbers are the same as in Figure 6.

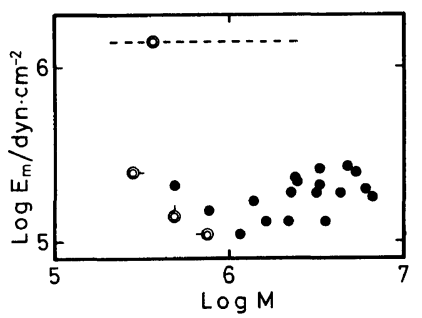

Figure 9. Molecular weight dependences of the relaxation modulus associated with the maximum relaxation time. The symbols are the same as in Figure 7.

four-armed, star-shaped polymers show almost the same behavior as highly branched, comb-shaped polymers in the undiluted state. It may also be concluded that linear and branched polymers display the same behavior in the short relaxation time region but different behaviors in the long relaxation time region. That is, in the terminal region, the relaxation time of branched polymers is made short and the distribution of the relaxation times of branched polymers is made broad, compared to those of linear polymers.

Acknowledgement. This work was supported by a grant from the Scientific Research Funds (Kagaku Kenkyu-hi, 847056-1973 and 1974) of the Ministry of Education, Japan.

\section{REFERENCES}

1. J. D. Ferry, "Viscoelastic Properties of Polymers," 2nd ed, Wiley, New York, N.Y., 1970.

2. W. W. Graessley, Adv. Polym. Sci., 16, 1 (1974).

3. P. A. Small, Adv. Polym. Sci., 18, 1 (1975).

4. W. W. Graessley, Accoun. Chem. Res., 10, 332 (1977).

5. S. Bywater, Adv. Polym. Sci., 30, 89 (1979).

6. T. Masuda, Y. Ohta, and S. Onogi, Macromolecules, 4, 763 (1971).

7. L. A. Utracki and J. E. L. Roovers, Macromolecules, 6, 366 (1973).

8. H. Kajiura, Y. Ushiyama, T. Fujimoto, and M. Nagasawa, Macromolecules, 11, 894 (1978).

9. T. Fujimoto, H. Narukawa, and M. Nagasawa, Macromolecules, 3, 57 (1970).

10. T. Fujimoto, H. Kajiura, M. Hirose, and $M$. Nagasawa, Polym. J., 3, 181 (1972).

11. K. Osaki, Y. Mitsuda, R. M. Johnson, J. L. Schrag, and J. D. Ferry, Macromolecules, 5, 17 (1972).

12. Y. Mitsuda, K. Osaki, J. L. Schrag, and J. D. Ferry, Polym. J., 4, 24 (1973).

13. J. S. Ham, J. Chem. Phys., 26, 625 (1957).

14. B. H. Zimm and R. W. Kilb, J. Polym. Sci., 37, 19 (1959).

15. A. J. Chompff, J. Chem. Phys., 53, 1577 (1970).

16. R. A. Mendelson, W. A. Bowles, and F. L. Finger, $J$. Polym. Sci., A-2, 8, 105, 127 (1970).

17. R. P. Chartoff and B. Mazwell, J. Polym. Sci., A-2, 8, 455 (1970).

18. W. W. Graessley, T. Masuda, J. E. Roovers, and H. Hadjichristidis, Macromolecules, 9, 127 (1976).

19. G. Kraus and J. T. Gruver, J. Polym. Sci., A, 3, 105 
Viscoelastic Properties of Branched Polymers. I.

(1965).

20. G. Kraus and J. T. Gruver, J. Polym. Sci., Polym. Phys. Ed, 8, 305 (1970).

21. J. E. L. Roovers and S. Bywater, Macromolecules, 5, 384 (1972).

22. T. Fujimoto, S. Tani, K. Takano, M. Ogawa, and M. Nagasawa, Macromolecules, 11, 673 (1978).

23. T. Fujimoto, N. Ozaki, and M. Nagasawa, J. Polym. Sci., $A-2$, 6, 129 (1968).

24. D. J. Plazek and A. J. Chelko, Jr., Polymer, 18, 15 (1977).

25. Y. Isono, T. Fujimoto, N. Takeno, H. Kajiura, and M. Nagasawa, Macromolecules, 11, 888 (1978).

26. F. Schwarzl and A. J. Staverman, Appl. Res., A4, 127 (1953).

27. A. V. Tobolsky, J. J. Aklonis, and G. Akovali, J. Chem. Phys., 42, 723 (1965).
28. G. Akovali, J. Polym. Sci., A-2, 5, 875 (1967).

29. D. J. Plazek, J. Polym. Sci., A-2, 6, 621 (1968).

30. D. J. Plazek and V. M. O'Rourke, J. Polym. Sci., A-2, 9, 209 (1971).

31. E. Riande, H. Markovitz, D. J. Plazek, and N. Raghupathi, J. Polym. Sci., Polym. Symp., No. 50, 405 (1975).

32. M. Sakai, T. Fujimoto, and M. Nagasawa, Macromolecules, 5, 786 (1972).

33. P. E. Rouse, J. Chem. Phys., 21, 1272 (1953).

34. F. Bueche, J. Chem. Phys., 22, 603 (1954).

35. B. H. Zimm, J. Chem. Phys., 24, 269 (1956).

36. Y. Isono, T. Fujimoto, $\mathrm{H}$. Kajiura, and $\mathbf{M}$. Nagasawa, in preparation.

37. A. V. Tobolsky and K. Murakami, J. Polym. Sci., 40, 443 (1959). 